\title{
AÇÕES ESTRUTURAIS, DIREITOS FUNDAMENTAIS E O ESTADO DE COISAS INCONSTITUCIONAL
}

Eduardo Sousa Dantas ${ }^{179}$

Recebido em: 21/10/2016

Aprovado em: 20/03/2017

\begin{abstract}
RESUMO
Esse artigo objetiva analisar as ações estruturais envolvendo graves violações de direitos fundamentais, as quais foram denominadas de estado de coisas inconstitucional pela jurisprudência da Corte Constitucional da Colômbia. Buscou-se, primeiramente, investigar a origem dessas ações a partir do julgamento de Brown vs. Board of Education, pela Suprema Corte dos Estados Unidos, bem como delimitar o conceito dessas ações, a fim de evitar a banalização desse instrumento. Buscou-se, ainda, enfrentar as principais críticas a essas ações, como as que se referem ao caráter ativista das decisões judiciais que interferem em políticas públicas. Sob uma perspectiva mais pragmática, investigou-se as técnicas decisórias aplicáveis a esses processos, que incluem medidas judiciais flexíveis acompanhadas de monitoramento, e a eficácia prática das decisões.
\end{abstract}

Palavras-chave: Direitos fundamentais. Demandas estruturais. Estado de coisas inconstitucional.

\section{INTRODUÇÃO}

Esse trabalho busca analisar as graves violações de direitos fundamentais deduzidas em demandas estruturais, figura que foi denominada na Colômbia de estado de coisas inconstitucional. Tais casos normalmente envolvem a violação generalizada de direitos fundamentais em virtude de falhas estruturais do Estado.

Os casos julgados pela Corte Constitucional colombiana possuem inspiração em demandas estruturais deduzidas nos Estados Unidos e Canadá, as quais servirão, portanto, como objeto de análise e comparação.

179 Mestrando em Direito Público pela Universidade Estadual do Rio de Janeiro. Bacharel em Direito pela Universidade Federal do Rio Grande do Norte. Juiz Federal. 
Além disso, o instituto foi recentemente introduzido no Brasil através do julgamento da Arguição de Descumprimento de Preceito Fundamental (ADPF) no 347 , que trata da situação do sistema prisional brasileiro. No julgamento da medida liminar nessa ação, inúmeras foram as referências ao estado de coisas inconstitucional.

Apesar disso, sua exata dimensão e aplicação ainda é pouco difundida no Brasil, tendo em vista a sua recente incorporação, o que vem causando dúvidas e confusões.

Nesse sentido, a importância do tema decorre da necessidade de se esclarecer como as Cortes Constitucionais podem atuar em demandas estruturais relativas a violações de direitos fundamentais que envolvam a atuação e atribuições normalmente conferidas aos demais poderes e órgãos públicos.

A hipótese que se pretende demonstrar é que situações de graves violações de direitos fundamentais exigem decisões judiciais que atuem no núcleo dessas falhas estruturais, apresentando novas alternativas e meios de solução para os casos. Objetiva-se, ainda, ter uma visão geral dessas técnicas decisórias.

\section{DEMANDAS ESTRUTURAIS E O ESTADO DE COISAS INCONSTITUCIONAL}

As demandas envolvendo falhas estruturais que violam direitos fundamentais iniciouse nos Estados Unidos, a partir do julgamento do caso Brown vs. Board of Education of Topeka, em 1954, célebre caso que decidiu sobre a segregação racial no sistema de ensino no sul dos Estados Unidos.

A Suprema Corte norte-americana, tendo ciência de que estaria promovendo uma verdadeira mudança social com massiva resistência dos conservadores do sul, adotou um modelo de progressiva superação da decisão que pôs fim ao precedente do equal but separated. Ainda assim, até meados da década de 1960, grande parte dos alunos negros ainda frequentava escolas segregadas ${ }^{180}$.

Com o julgamento do caso Swan vs. Charlotte-Mecklenburg Board of Education, em 1971, a Corte atuou de forma mais incisiva, tendo rejeitado os três planos de apresentado pelos

${ }^{180}$ Cf. WEAVER, Russel. The rise and decline of structural remedies. San Diego Law Review: V. 41, 2004. p. 1619. 
órgãos de ensino e decidido realizar por conta própria a desegregação, mediante ordens estruturais a serem cumpridas pelo Estado ${ }^{181}$.

Como consequência dessa mudança, o professor Russel L. Weaver destaca que as Cortes Federais impuseram diversas ordens estruturais em um significativo número de demandas questionando a desagregação racial nas escolas, o que culminou com uma verdadeira reforma de todo o sistema de ensino nos Estados Unidos ${ }^{182}$.

Além dos casos da segregação racial nas escolas, ações e decisões desse tipo foram utilizadas em casos relativos às péssimas condições das prisões norte-americanas, descritas como "um lugar escuro e sombrio completamente dissociado do mundo livre". Também foram aplicadas em processos envolvendo a reforma de estabelecimentos de saúde e instituições psiquiátricas que possuíam estruturas e procedimentos que violavam o direito à saúde dos pacientes e internos ${ }^{183}$.

No Canadá, ações semelhantes, envolvendo, principalmente, o direito à educação bilíngue estabelecido pelo art. 23 da Carta de Direitos de $1982^{184}$, foram julgados a partir de 1996, haja vista a reiterada omissão estatal na implementação desse direito ${ }^{185}$.

$\mathrm{Na}$ Colômbia, essas demandas estruturais foram incorporadas pela jurisprudência da Corte Constitucional Colombiana, com algumas modificações, tendo recebido o tratamento e a denominação de estado de coisas inconstitucional.

Tratando especificamente do contexto colombiano, Libardo Ariza ${ }^{186}$ defende que há a configuração desse instituto nos casos de violações massivas e generalizadas de direitos fundamentais decorrentes de deficiências nos arranjos institucionais do Estado.

\footnotetext{
181 idem, p. 1620.

182 idem, p. 1618 e ss.

183 idem, p. 1618.

184"23. (1) Cidadãos do Canadá (a) os quais a primeira língua aprendida e compreendida é o inglês ou francês, constituindo parte da minoria linguística da população de uma província em que eles residem ou (b) os quais receberam instrução no ensino primário no Canadá em inglês ou francês, constituindo parte da minoria linguística da população de uma província em que eles residem tem o direito de ter suas crianças educadas no ensino primário e secundário nessa língua dentro da província." CANADÁ. Carta Canadense de Direitos e Liberdades. 1982. Disponível em: < http://laws-lois.justice.gc.ca/eng/const/page-15.html>. Acesso em 12/10/2015, às 19h:12m.

185 Cf. ROULEAU, Paul S.; SHERMAN, Lindsey. Doucet-Boudreau, dialogue and judicial activism: tempest in a teapot? Ottawa Law Review: V. 41.2. 2010.

${ }^{186}$ Cf. ARIZA, Libardo José. The Economic and Social Rights of Prisoners and Constitutional Court Intervention in the Penitentiary System in Colombia. In: MALDONADO, Daniel Bonilla. Constitutionalism of the Global South. The Activist Tribunals of India, South Africa and Colombia. New York: Cambridge University Press, 2013, p. 129.
} 
Cesar Garavito Rodriguéz ${ }^{187}$, por sua vez, destaca que a jurisprudência do estado de coisas inconstitucional da Corte Constitucional Colombiana envolve litígios estruturais dotados das seguintes características: $i$ ) alegações de violações de direitos fundamentais de um número significativo de pessoas, seja diretamente ou através de organizações; ii) envolvimento de diversos órgãos estatais responsáveis por falhas estruturais na implementação de políticas públicas;

Para o professor Carlos Alexandre de Azevedo Campos ${ }^{188}$, a Corte Colombiana tem feito uso desse instrumento para a proteção da dimensão objetiva dos direitos fundamentais, utilizando-o para declaração da própria deficiência ou imperfeição de leis e políticas públicas, suas formulações e implementações, que gerem a violação massiva de direitos fundamentais.

Dentre os casos nos quais houve o reconhecimento desse estado de coisas, podemos destacar a situação de absoluta ausência de cobertura previdenciária de professores públicos municipais na Colômbia ${ }^{189}$, a violação maciça ao direito de petição dos segurados da Previdência Social pela não apreciação de requerimentos administrativos ou apresentação de respostas-padrão sem análise dos pedidos ${ }^{190}$, lesões aos direitos à saúde, integridade física e psíquica, vida e dignidade dos detentos recolhidos em prisões superlotadas ${ }^{191}$ e negação dos direitos à moradia, ao trabalho, saúde, alimentação e educação da população vítima de deslocamento forçado em virtude dos conflitos armados ${ }^{192}$.

Ao julgar o caso do deslocamento forçado de pessoas, a Corte Constitucional Colombiana elencou os seguintes requisitos, necessários à configuração dessa situação ${ }^{193}$ : (i) a violação massiva e generalizada de vários direitos constitucionais que afetam um número significativo de pessoas; (ii) a prolongada omissão das autoridades no cumprimento de suas obrigações de garantia desses direitos; (ii) a adoção de práticas inconstitucionais, como a incorporação de ações judiciais como parte do procedimento exigido para a garantia dos direitos violados; (iii) a não expedição de medidas legislativas, administrativas ou orçamentárias

187 Cf. RODRIGUÉZ, Cesar Garavito. Más alla del desplaziamento o como superar un estado de cosas inconstitucional. In: RODRIGUÉZ, Cesar Garavito (Coord.). Más alla del desplaziamento políticas, derechos y superación del desplazamiento forzado en Colombia. Bogotá: Universidad de los Andes, Facultad de Derecho, Ediciones Uniandes, 2009. p. 435.

188 CAMPOS, Carlos Alexandre de Azevedo. Da inconstitucionalidade por omissão ao "Estado de Coisas Inconstitucional". Tese de Doutorado. UERJ: Rio de Janeiro, 2015. p. 134.

${ }^{189}$ COLÔMBIA. Corte Constitucional. Sentença Sentença T-559-97

${ }^{190}$ COLÔMBIA. Corte Constitucional. Sentença Sentença T 525-99

${ }^{191}$ COLÔMBIA. Corte Constitucional. Sentença Sentença T-153-98

192 COLÔMBIA. Corte Constitucional. Sentença T-025/04. Terceira Sala de Revisão. Rel. Juiz Manuel José Cepeda-Espinoza. J. 22/01/2004. p. 72.

193 COLÔMBIA. Corte Constitucional. Sentença T-025/04. Terceira Sala de Revisão. Rel. Juiz Manuel José Cepeda-Espinoza. J. 22/01/2004. p. 71 e ss. 
necessárias para evitar a violação dos direitos; (iv) a existência de um problema social cuja solução requer a intervenção de várias entidades e a adoção de um conjunto completo e coordenado de ações, além de acréscimo de recursos que demandam um esforço orçamentário importante; $(v)$ o congestionamento judicial caso todas as pessoas afetadas pelo mesmo problema procurassem o Poder Judiciário para obter a tutela de seus direitos.

É importante ressaltar que tais declarações ocorreram no julgamento de ações de tutela que apreciam casos individuais. No entanto, a partir da constatação genérica da violação massiva a direitos fundamentais, a Corte conferiu eficácia geral e erga omnes às decisões, que passaram a aproveitar todos os demais indivíduos que se encontrassem em idêntica situação ${ }^{194}$.

Segundo Libardo Ariza ${ }^{195}$, a declaração dessa situação fática de inconstitucionalidade possibilita a assunção, por parte da Corte Constitucional, da atribuição de estabelecer políticas públicas e a alocação de recursos, assumindo funções que seriam tipicamente do Poder Legislativo no esquema tradicional de separação de poderes.

Além dessa função, a superação da situação de inconstitucionalidade requer a expedição de ordens de execução complexas, mediante a qual o Juiz da causa instrui diversos órgãos a agirem coordenadamente para protegerem toda a população afetada ${ }^{196}$.

É importante destacar que decisões estruturais, como aquelas que declaram a existência de um estado de coisas inconstitucional, constituem exemplo de remedial ativism, na classificação de William P. Marshal ${ }^{197}$, ou seja, decisões que impõem obrigações judiciais contínuas aos outros poderes, mediante supervisão judicial, como medida adequada à correção da situação de inconstitucionalidade verificada.

Também podem ser classificadas como decisões ativistas sob as dimensões estrutural e de direitos, conforme defendido pelo professor Carlos Alexandre de Azevedo Campos ${ }^{198}$, uma vez que interferem incisivamente sobre as decisões dos demais poderes, avançando em questões de liberdade, dignidade e igualdade e interferindo em questões de escolhas de políticas públicas.

\footnotetext{
${ }^{194}$ COLÔMBIA. Corte Constitucional. Sentença Sentença T-025-04

195 Cf. ARIZA, Libardo José. The Economic and Social Rights of Prisoners and Constitutional Court Intervention in the Penitentiary System in Colombia. In: MALDONADO, Daniel Bonilla. Constitutionalism of the Global South. The Activist Tribunals of India, South Africa and Colombia. New York: Cambridge University Press, 2013, p. 129.

196 Cf. RODRIGUÉZ, Cesar Garavito. Más alla del desplaziamento o como superar un estado de cosas inconstitucional. In: RODRIGUÉZ, Cesar Garavito (Coord.). Más alla del desplaziamento políticas, derechos y superación del desplazamiento forzado en Colombia. Bogotá: Universidad de los Andes, Facultad de Derecho, Ediciones Uniandes, 2009. p. 435.

${ }^{197}$ MARSHALL, Willian P. Conservatives and the seven sins of judicial activism. University of Colorado Law Review, Vol. 73, 2002. p. 104.

198 CAMPOS, Carlos Alexandre de Azevedo. Da inconstitucionalidade por omissão ao "Estado de Coisas Inconstitucional". Tese de Doutorado. UERJ: Rio de Janeiro, 2015. p. 176.
} 
Para o professor americano Owen Fiss, que criou essa denominação, as ações estruturais são aquelas nas quais o juiz confronta a burocracia estatal em relação ao cumprimento de valores constitucionais e tenta reestruturar determinada organização ou instituição, eliminando a ameaça que ela representa a esses valores e direitos em virtude do atual arranjo institucional $^{199}$.

Segundo o autor, a premissa dessas ações é a noção de que as qualidades da vida social dos indivíduos são afetadas pelo funcionamento de organizações que atuam em larga escala ${ }^{200}$, tal como ocorre, no Brasil, com os presídios, as escolas, as unidades de saúde e os gestores públicos responsáveis pelos serviços de saneamento básico, urbanização e moradia.

Nesse sentido, essas ações buscam tutelar não um incidente concreto, mas o próprio funcionamento dessas organizações ${ }^{201}$. O objetivo não é a reparação de uma lesão ocorrida no passado, mas a eliminação de uma ameaça contínua a valores constitucionais representados pelos direitos fundamentais dos indivíduos ${ }^{202}$.

Trata-se, portanto, de ações que buscam tutelar direitos fundamentais e reorganizar instituições que provocam violações aos direitos dos indivíduos em virtude de falhas estruturais e da má performance no exercício de suas atribuições.

\section{AS CRÍTICAS AO CARÁTER ATIVISTA DAS DECISÕES}

Para a melhor compreensão das decisões proferidas em demandas estruturais e das suas hipóteses de cabimento, é importante enfrentar as principais críticas que podem ser suscitadas à utilização dessas decisões, em especial no que toca ao seu caráter ativista.

De acordo com o professor Luís Roberto Barroso ${ }^{203}$, a ideia de ativismo judicial está associada a uma participação mais ampla e intensa do Judiciário na realização dos fins e valores constitucionais, com maior interferência no espaço de atuação dos outros dois poderes.

\footnotetext{
${ }^{199}$ FISS, Owen. Foreword: The Forms of Justice. Harvard Law Review. Vol. 93. nº 1. nov. 1979. p. 2

200 idem, p. 2

201 idem, p. 18

202 idem, p. 23.

${ }^{203}$ BARROSO, Luís Roberto. O novo direito constitucional brasileiro. Ed. Fórum: 2012, p. 250.
} 
A expressão foi primeiramente utilizada pelo historiador norte-americano Arthur M. Schlensiger, em artigo publicado em revista de ampla circulação, no período ativista da Suprema Corte dos Estados Unidos do New Deal ${ }^{204}$, entre 1954 e 1969.

Barroso continua demonstrando que durante esse período ocorreram significativas transformações nas práticas políticas dos Estados Unidos, no que toca à proteção de direitos fundamentais, sem que houvesse qualquer ato do Congresso ou Decreto Presidencial ${ }^{205}$.

Tal situação levou a uma intensa reação por parte de uma corrente de pensamento conservadora $^{206}$, de modo que a expressão adquiriu uma conotação negativa "equiparada ao exercício impróprio do poder judicial"207.

Posteriormente, com a mudança da composição do tribunal e a adoção de decisões conservadoras, essas críticas também foram endossadas pelas correntes de pensamento progressistas $^{208}$.

Entre as principais críticas ao ativismo judicial, destacam-se: a crítica de caráter institucional, a crítica de caráter democrático e a crítica liberal.

Cass Sunstein e Adrian Vermule foram dois dos autores norte-americanos que melhor formularam a crítica de caráter institucional.

Para eles, ao invés de se perguntarem "como, em princípio, um texto deve ser interpretado?", os juristas e teóricos do Direito deveriam se perguntar "como deveriam certas Instituições, com suas distintas habilidades e limitações, interpretar certos textos?"209.

Portanto, ao invés do Juiz Hércules de Dworkin, que busca a integridade do Direito elevando o substrato legal à melhor luz possível ${ }^{210}$, deve-se considerar a existência de Juízes falíveis $^{211}$, com limitações de tempo, em um sistema complexo com efeitos sistêmicos de larga escala que escapam à percepção do Poder Judiciário ao decidir casos concretos ${ }^{212}$.

Ao final, o que esses autores defendem é que falta ao Poder Judiciário, em inúmeros casos, a capacidade institucional específica, a expertise ou conhecimento técnico para anular decisões tomadas pelos poderes Executivo e Legislativo. Nesses casos, devem os juízes ser

\footnotetext{
204 ibidem, p. 271. nota de rodapé 21.

205 ibidem, p. 250.

206 ibidem, p. 250.

207 ibidem, p. 250.

${ }^{208}$ LIPKIN, Robert Justin. What's Wrong With Judicial Supremacy? What's Right About Judicial Review? Widener Law Review. Vol. 14. P. 3-4.

${ }^{209}$ SUNSTEIN, Cass R; VERMULE, Adrian. Interpretation and Institutions. John M. Olin Program in Law and Economics Working Paper. No. 156. Chicago, 2002. p. 2.

210 ibidem, p. 14.

211 ibidem, p. 47.

212 ibidem, p. 35.
} 
deferentes às escolhas tomadas pelos demais poderes, evitando a anulação ou alteração de leis através da utilização de recursos como o formalismo e/ou minimalismo judicial ${ }^{213}$.

Em relação à crítica democrática, ela foi originariamente vislumbrada por Alexander Bickel, em sua influente obra The Least Dangerous Branch: The Supreme Court at the Bar of Politics, publicada em 1962. Para o autor, o controle de constitucionalidade exercido pela Suprema Corte norte-americana representaria uma força contramajoritária no sistema democrático, ainda que os Juízes defendessem sua atuação em nome do povo, considerado abstratamente ${ }^{214}$.

Para o autor, ao declarar a inconstitucionalidade de uma norma legislativa promulgada por representantes eleitos pelo povo ou uma ação elaborada por agente eletivo do executivo, a Suprema Corte não exerceria o controle em favor da atual maioria prevalente, mas sim contra essa mesma maioria, o que caracterizaria a dificuldade contramajoritária atribuída ao poder judiciário $^{215}$.

Nesse sentido, Bickel defendia que quando uma questão submetida à Suprema Corte não estivesse de acordo com a opinião popular, o tribunal deveria se utilizar das virtudes passivas para evitar essas questões até o tempo em que a sociedade pudesse debater suficientemente o assunto ${ }^{216}$.

Após a divulgação dessa teoria, a crítica democrática ao controle de constitucionalidade passou a ser a obsessão central da teoria constitucional norte-americana, que se debruça sobre esse debate até os dias atuais ${ }^{217}$.

Um dos autores que melhor desenvolveu essa crítica ao extremo foi o filósofo neozelandês Jeremy Waldron, em seu livro Law and disagreement.

Para Waldron, considerando que as pessoas discordam dos direitos que elas devem possuir, a definição de tais direitos deve ser realizada através do processo político democrático ${ }^{218}$.

\footnotetext{
${ }^{213}$ SUNSTEIN, Cass R; VERMULE, Adrian. Interpretation and Institutions. John M. Olin Program in Law and Economics Working Paper. No. 156. Chicago, 2002. p. 47 e ss.

${ }^{214}$ BICKEL, Alexander M. The Least Dangerous Branch: The Supreme Court at the Bar of Politics. 2 ed. Yale University Press: New Haven, 1962. p. 16.

${ }^{215}$ Idem, p. 16-17.

${ }^{216}$ FRIEDMAN, Barry. The Birth of an Academic Obsession: The History of The Countermajoritarian Difficulty, Part Five. 112 Yale Law Journal. 153. 2002-2003. p. 201.

${ }^{217}$ FRIEDMAN, Barry. The Birth of an Academic Obsession: The History of The Countermajoritarian Difficulty, Part Five. 112 Yale Law Journal. $n^{\circ}$ 153. 2002-2003.

${ }^{218}$ WALDRON, Jeremy. Law and disagreement. Oxford University Press: Nova Iorque, 2004. p. 239.
} 
Segundo o autor, ao se deparar com a pergunta sobre quem deve definir os direitos das pessoas, a resposta é que as próprias pessoas envolvidas devem decidir mediante o exercício do igual direito de participação no processo político ${ }^{219}$, em especial através do Parlamento.

Portanto, a garantia de direitos mediante o "entricheiramento constitucional" de tais direitos e do controle judicial não seria um critério de autoridade legítimo e válido para se decidir acerca dessas questões. Tratar-se-ia, na verdade, de mecanismo antidemocrático de resolução de disputas que deveria ser substituído pelos mecanismos democráticos majoritários $\operatorname{propostos}^{220}$.

No que toca à crítica liberal, ela decorre da ideia do liberalismo moderno de divisão do poder enquanto garantia dos cidadãos. Nesse sentido, as decisões judiciais em demandas estruturais violariam o princípio da separação dos poderes, tendo em vista que caberia aos demais poderes, em especial ao legislativo, o estabelecimento e a implantação de políticas públicas, sendo atribuído ao poder judiciário apenas questões de princípios ou de direitos fundamentais $^{221}$.

Em relação às críticas institucional e democrática, é importante assinalar, em primeiro lugar, que os casos de graves violações de direitos fundamentais típicos do estado de coisas inconstitucional por vezes não envolvem grandes divergências acerca da existência, definição ou conteúdo do direito em disputa já que na maioria das situações, as violações aos direitos fundamentais são flagrantemente inconstitucionais.

Com efeito, os casos até então julgados envolvem a ausência total de cobertura previdenciária a professores municipais ${ }^{222}$, a não apreciação de requerimentos administrativos de segurados da Previdência Social que necessitam da fruição de benefícios para sua sobrevivência ${ }^{223}$, a flagrante violação à saúde, integridade física e psíquica, vida e dignidade de detentos reclusos em prisões superlotadas, sem abastecimento de água, ventilação adequada, tratamento de esgoto e observância do espaço individual mínimo previsto pela legislação ${ }^{224}$, e

\footnotetext{
219 ibidem, p. 240

${ }^{220} \mathrm{Em}$ artigo mais recente sobre o assunto, Waldron escreve que o funcionamento de sua teoria pressupõe a existência das seguintes circunstâncias: (1) instituições democráticas em bom funcionamento, inclusive através da eleição de um corpo de representantes através do sufrágio universal; (2) um conjunto de instituições judiciais em bom funcionamento, em bases não representativas, para conhecer de demandas individuais e resolver disputas com base no princípio da supremacia da lei; (3) um comprometimento da maioria da sociedade com os direitos individuais e das minorias; (4) a persistente e substancial discordância das pessoas acerca da definição e conteúdo dos direitos. WALDRON, Jeremy. The core of the case against judicial review. The Yale Law Journal, 115.

${ }^{221}$ BRANDÃO, Rodrigo. Supremacia judicial versus diálogos constitucionais: a quem cabe a última palavra sobre o sentido da Constituição? Rio de Janeiro: Lumen Juris, 2012. p. 223.

${ }^{222}$ COLÔMBIA. Corte Constitucional. Sentença Sentença T-559-97

${ }^{223}$ COLÔMBIA. Corte Constitucional. Sentença T 525-99

${ }^{224}$ COLÔMBIA. Corte Constitucional. Sentença T 153-98
} 
a violação aos mais elementares direitos à moradia, ao trabalho, à educação e à dignidade de pessoas deslocadas de suas residências pelos conflitos armados na Colômbia ${ }^{225}$.

Em outras palavras, nesses casos, o foco da questão não é sobre a existência ou a delimitação de um direito fundamental, o debate público ou a aceitação popular acerca da existência desse direito, mas sim como concretizar ou garantir minimamente direitos básicos dos indivíduos já definidos pelos poderes democráticos diante de uma situação de prolongada inércia e omissão do Poder Público.

Portanto, não se está diante de casos difíceis que envolvem a definição do conteúdo de conceitos jurídicos indeterminados ou de desacordos morais razoáveis em relação ao aborto ou a eutanásia, por exemplo, no qual a crítica democrática de Jeremy Waldron é mais contundente.

É importante acrescentarmos que o debate sobre a crítica democrática adota, por vezes, uma postura maniqueísta, recheado de idealismos, com a exaltação, de um lado, das virtudes dos parlamentares enquanto legítimos representantes do povo e, do outro, da figura dos juízes enquanto autênticos intérpretes do poder constituinte originário e da vontade popular ${ }^{226}$.

Tal postura simplifica a discussão e ignora as virtudes e fraquezas de cada poder, como um todo. Além disso, dificulta a elaboração de uma teoria realista, que inclua todos os poderes na produção de normas jurídicas e estabelecimento de políticas públicas, onde a "disputa pela escolha da norma que regulará determinada situação tende a produzir um processo deliberativo mais qualificado do que a mítica associação de um departamento estatal à vontade constituinte do povo"227.

Ainda no que toca à crítica democrática, é importante registrar que as decisões judiciais podem ser dotadas de legitimidade democrática argumentativa através da ampliação do acesso à justiça e instauração de debate público sobre determinada demanda, com a participação de todos os interessados na questão e escrutínio público das razões e argumentos suscitados por cada uma das partes ${ }^{228}$.

Acresça-se que diversas violações sistêmicas de direitos fundamentais podem ser praticadas por agentes públicos que se encontram nos níveis inferiores da administração

\footnotetext{
${ }^{225}$ COLÔMBIA. Corte Constitucional. Sentença T 025-04

${ }^{226}$ BRANDÃO, Rodrigo. Supremacia judicial versus diálogos constitucionais: a quem cabe a última palavra sobre o sentido da Constituição? Rio de Janeiro: Lumen Juris, 2012. p. 221.

227 idem, p. 221.

${ }^{228}$ sobre o assunto, confira: GARGARELLA, Roberto. Theories of Democracy, Judiciary and Social Rights. In: Courts and Social Transformations in New Democracies. An institutional voice for the poor?. Ashgate: Hampshire, 2006. BARROSO, Luís Roberto. A razão sem voto: o Supremo Tribunal Federal e o Governo da Maioria. In: Jurisdição constitucional e política. Coord.: SARMENTO, Daniel. Rio de Janeiro: Forense, 2015.
} 
pública $^{229}$, como no caso de funcionários do sistema carcerário que impõem penas de isolamento ou tortura cruéis e injustas a detentos. Nesse caso, a crítica democrática perde força, pois não se está contraponto o judiciário com o chefe do executivo eleito pelo povo.

Em outras situações, as violações decorrem não de uma ação ou política pública debatida nas eleições e chancelada pelo voto popular, mas sim de uma omissão ou ponto cego no debate público, o que também retira a força desse argumento democrático ${ }^{230}$.

No que toca a crítica institucional, o ponto mais importante refere-se à falta de informações sobre os meios para implementação da decisão que reconhece as graves violações de direitos fundamentais. Para os críticos, nesses casos o judiciário deveria ser deferente à expertise técnica do poder executivo.

No entanto, qual o grau de deferência deve ser atribuído ao poder que exerce suas atribuições técnicas de forma defeituosa, causando graves lesões aos direitos dos cidadãos? Há, evidentemente, uma supervalorização dessa expertise que não se verifica na prática ${ }^{231}$.

Ademais, a questão é posta de uma forma excessivamente simplória: deferência ao poder executivo ou assunção dessas funções pelo órgão judicial. Essa situação configura, conforme defende Charles Sabel e William Simon, uma falsa dicotomia ${ }^{232}$, uma vez que na prática é possível adotar um modelo decisório que privilegie a capacidade institucional específica dos órgãos públicos envolvidos, o diálogo institucional e as credenciais democráticas dos demais poderes.

Nesse modelo mais realista as Cortes Constitucionais atuam para tentar superar as graves violações de direitos fundamentais e a inércia dos órgãos estatais, porém com a ampla participação dos demais poderes envolvidos através de debates públicos sobre o assunto e a apresentação de informações e contribuições necessárias à solução do caso.

Tal modelo deve influir inclusive sobre as técnicas decisórias a serem adotadas, já que nesses casos as Cortes Constitucionais têm adotado medidas judiciais flexíveis ${ }^{233}$ ou remédios estruturais (structural remedies) ${ }^{234}$ sujeitos à supervisão judicial e monitoramento das medidas

\footnotetext{
${ }^{229}$ SABEL, Charles F.; SIMON, William H. Destabilization rights: how public law litigation suceeds. Harvard Law Review. 117. February, 2004. p. 1066.

${ }^{230}$ Idem, p. 1065.

${ }^{231}$ Idem, p. 1061.

232 Idem, p. 1059.

${ }^{233}$ ROULEAU, Paul S.; SHERMAN, Lindsey. Doucet-Boudreau, dialogue and judicial activism: tempest in a teapot? Ottawa Law Review: V. 41.2. 2010. p. 179.

${ }^{234}$ Cf. WEAVER, Russel. The rise and decline of structural remedies. San Diego Law Review: V. 41, 2004. p. $1617-1632$
} 
adotadas. Trata-se de situação na qual há a retenção da jurisdição pela Corte Constitucional $^{235}$, inclusive para rever a ordem proferida ou as medidas adotadas à superação da situação de inconstitucionalidade.

No que toca à crítica liberal, essa objeção se sustenta em um modelo liberal clássico de jurisdição constitucional que visualiza o princípio da separação dos poderes de forma estanque e estática, simbolizado através da dicotomia Legislativo/questões de política e Judiciário/questões de princípios $^{236}$.

Não obstante, conforme claramente demonstrado pelo professor Rodrigo Brandão em sua obra sobre os diálogos constitucionais, esse modelo de separação estanque das funções estatais por vezes se confunde, uma vez que diversas questões de direitos estão umbilicalmente conectadas com questões de políticas públicas. Nesse sentido, o professor destaca que tais questões podem ser decididas em fóruns políticos superpostos e diversamente representativos, incluindo o Poder Judiciário ${ }^{237}$.

Trata-se de uma concepção mais fluida do princípio da separação dos poderes adotada pelos Estados Unidos desde a concepção da Constituição norte-americana de 1776 pelos founding fathers, em especial pelo pensamento de James Madison ${ }^{238}$.

\section{AS HIPÓTESES E OS LIMITES DAS DECISÕES ESTRUTURAIS}

É importante que seja esclarecido quais são as hipóteses e os limites das decisões estruturais que concretizam direitos fundamentais mediante interferência significativa na atuação dos demais poderes e órgãos públicos.

Isso porque a não delimitação das hipóteses e da extensão das medidas poderia dar a falsa impressão de que tais decisões podem ser aplicadas de qualquer forma e a qualquer caso, o que contribuiria para a má compreensão e vulgarização desse instrumento, prejudicando o pleno desenvolvimento de suas potencialidades.

\footnotetext{
${ }^{235}$ ROULEAU, Paul S.; SHERMAN, Lindsey. Doucet-Boudreau, dialogue and judicial activism: tempest in a teapot? Ottawa Law Review: V. 41.2. 2010. p. 174.

${ }^{236}$ BRANDÃO, Rodrigo. Supremacia judicial versus diálogos constitucionais: a quem cabe a última palavra sobre o sentido da Constituição? Rio de Janeiro: Lumen Juris, 2012. p. 223.

${ }^{237}$ BRANDÃO, Rodrigo. Supremacia judicial versus diálogos constitucionais: a quem cabe a última palavra sobre o sentido da Constituição? Rio de Janeiro: Lumen Juris, 2012. p. 221.

238 ibidem, p. 221.
} 
Deveras, a análise dos casos envolvendo a aplicação de decisões estruturais permite traçar algumas diretrizes sobre as hipóteses e limites de sua aplicação. Para alcançar esse objetivo, é necessário que sejam expostas as ideias e os critérios estabelecidos no estudo de Paul Rouleau e Lindsey Sherman sobre as decisões estruturais no Canadá, e Russel Weaver sobre remédios estruturais nos Estados Unidos.

Para os dois primeiros autores, a primeira hipótese que justifica essa modalidade de decisão é a existência da recalcitrância ou prolongada inércia do Poder Público na implementação de direitos fundamentais ${ }^{239}$.

Portanto, quando houver uma situação de prolongada inércia do Poder Público, como nos casos da educação francófona no Canadá, dos presos nos Estados Unidos e das vítimas de deslocamentos forçados na Colômbia, é possível optar por uma decisão estrutural flexível acompanhada de supervisão judicial.

A segunda circunstância é o grau de urgência da decisão. Nos casos em que essa reiterada omissão do Poder Público possa causar danos irreparáveis aos indivíduos lesados, a adoção de decisões mais incisivas que determinem a atuação estatal imediata para a concretização de direitos é medida necessária e adequada para prevenir a ocorrência desses $\operatorname{danos}^{240}$.

Em terceiro lugar, as decisões estruturais não são aplicáveis aos casos que podem ser decididos através de uma decisão simples, denominados de one-stop shop remedies ${ }^{241}$. Ou seja, quando uma decisão específica for suficiente para reparar a lesão, não se deve utilizar de medidas mais amplas.

Por outro lado, quando o processo de implementação envolver situações complexas com diversas variáveis e atores sociais, exigindo a implementação gradual e progressiva, como ocorre com a maioria dos litígios estruturais, haverá a necessidade de utilização de decisões estruturais flexíveis ${ }^{242}$.

Além disso, os autores ainda defendem que as decisões judiciais somente se justificam quando houver um consenso político sobre os direitos em disputa, pois quando houver dúvidas acerca da existência ou conteúdo do direito, deve-se deixar que a questão seja decidida pelo

\footnotetext{
${ }^{239}$ ROULEAU, Paul S.; SHERMAN, Lindsey. Doucet-Boudreau, dialogue and judicial activism: tempest in a teapot? Ottawa Law Review: V. 41.2. 2010. p. 185-186.

${ }^{240}$ ROULEAU, Paul S.; SHERMAN, Lindsey. Doucet-Boudreau, dialogue and judicial activism: tempest in a teapot? Ottawa Law Review: V. 41.2. 2010. p. 186.

241 ibidem, p. 187.

242 ibidem, p. 187.
} 
Poder Legislativo, que possui maior capacidade institucional em captar a vontade popular e conciliar os interesses em jogo 243 .

Por sua vez, Russel Weaver reconhece o caráter ativista dessas decisões e entende que elas devem ser utilizadas como último recurso (last resort) ${ }^{244}$. O autor acrescenta, ainda, que essas decisões devem se limitar a corrigir a violação constitucional verificada, não devendo durar mais do que o tempo estritamente necessário ${ }^{245}$.

Exemplificando o seu raciocínio, o autor cita o julgamento do caso Missouri vs. Jenkins, dentro do contexto da desegregação racial no sistema de ensino nos Estados Unidos ${ }^{246}$. Nesse caso, a Corte local concluiu ela existência de segregação dentro do distrito escolar de Missouri, Kansas City, no qual $68 \%$ dos alunos inscritos eram negros ${ }^{247}$.

O ponto nevrálgico, no entanto, referia-se à dificuldade de redesignar estudantes de modo a eliminar a segregação racial, em especial pelo receio de que a transferência de estudantes não-minoritários de outros distritos, para criar a integração, pudesse levar à evasão escolar e instabilidade do sistema de ensino ${ }^{248}$.

Para resolver o problema, a Corte decidiu melhorar o sistema de ensino do distrito na esperança de que tal medida pudesse atrair estudantes não-minoritários para o distrito, criando "atração desagregativa" (desegregative attractiveness). Para tanto, o Tribunal permitiu que os diretores do distrito idealizassem as mudanças que entendessem necessárias para melhorar o sistema, através de recursos garantidos judicialmente através de ordens dirigidas ao Estado.

Tais ordens levaram à previsão de gastos de elevadas quantias, que totalizavam aproximadamente U\$ 928 milhões de dólares com a qualidade da educação, melhorias de infraestrutura, dentre outras medidas ${ }^{249}$.

Analisando o caso, a Suprema Corte dos Estados Unidos decidiu que a Corte local excedeu sua autoridade ao focar na atração desagregativa financiada com recursos estatais, uma vez que a ação visava a eliminação da desagregação racial dentro do distrito de Missouri, Kansas City, e não a transferência de alunos entre distritos diversos ${ }^{250}$. Além disso, o Tribunal resolveu que a decisão adotada não possuía nenhuma limitação objetiva, inclusive quanto ao

\footnotetext{
243 ibidem, p. 187.

${ }^{244}$ WEAVER, Russel. The rise and decline of structural remedies. San Diego Law Review: V. 41, 2004. p. 1629.

245 ibidem, p. 1631.

246 idem, p. 1622.

247 idem, p. 1622.

248 idem, p. 1622.

249 idem, p. 1622.

${ }^{250}$ WEAVER, Russel. The rise and decline of structural remedies. San Diego Law Review: V. 41, 2004. p. 1623.
} 
tempo de duração do envolvimento da Corte, o que estava em desacordo com os precedentes existentes para os casos de desegregação no sistema de ensino público ${ }^{251}$.

Portanto, as demandas estruturais devem ser utilizadas como última medida para a superação de graves violações de direitos fundamentais e os Tribunais devem se restringir ao caso posto em julgamento, exercendo a jurisdição pelo estrito tempo necessário à superação da situação de inconstitucionalidade verificada. Tal conclusão também pode ser extraída da análise sistemática das hipóteses e requisitos trazidos pela doutrina canadense acerca dessas espécies de ações, o que demonstra a aplicação estrita dessas decisões aos casos mais graves de violações de direitos fundamentais por inércia ou falhas estruturais significativas do Poder Público.

\section{MEDIDAS JUDICIAIS FLEXÍVEIS E MONITORAMENTO}

Os órgãos judiciais se utilizam, tradicionalmente, de técnicas de decisões rígidas e fechadas para o cumprimento de suas determinações, que devem seguir o procedimento de execução estabelecido por lei, sem a possibilidade de qualquer participação do executado na definição do conteúdo da decisão ou dos meios utilizados para se chegar ao fim.

Trata-se das decisões que contém ordens detalhadas e rígidas no qual o Juiz define concretamente a medida a ser adotada e fiscaliza o cumprimento da ordem ${ }^{252}$.

No entanto, nos casos de demandas estruturais, a jurisdição constitucional tem optado por adotar decisões declaratórias da situação de inconstitucionalidade (declaratory orders) ${ }^{253}$, com a determinação de que os poderes públicos superem essa situação, porém com a imposição das medidas abertas e flexíveis.

$\mathrm{Na}$ Colômbia existem dois grandes exemplos nos quais foram utilizadas essas técnicas decisórias: o caso da superpopulação carcerária e o caso do deslocamento forçado de pessoas.

No caso da superpopulação carcerária, o Tribunal Constitucional, após notificar todas autoridades responsáveis acerca da ocorrência do estado de coisas inconstitucional, ordenou ao Instituto Penitenciário Nacional (INPEC), ao Ministério da Justiça e ao Departamento Nacional de Planejamento que elaborassem, em três meses, um plano nacional de construção e reforma

\footnotetext{
251 idem, p. 1623.

${ }^{252}$ ROULEAU, Paul S.; SHERMAN, Lindsey. Doucet-Boudreau, dialogue and judicial activism: tempest in a teapot? Ottawa Law Review: V. 41.2. 2010. p. 181.

253 ibidem. p. 179.
} 
carcerária que garantissem condições de vida dignas aos presos, o qual seria fiscalizado, nesse ponto, pela Procuradoria Geral da Nação e pelo Defensor do Povo ${ }^{254}$.

Da mesma forma, no caso do deslocamento forçado de pessoas, a Corte declarou a existência de um estado de coisas inconstitucional e ordenou ao Conselho Nacional de Atenção Integral às pessoas deslocadas que elaborasse um plano de ação, com cronograma preciso, para que as falhas nas capacidades institucionais dos órgãos envolvidos fossem corrigidas em 3 (três) meses e para que as vítimas desse deslocamento gozassem dos direitos mínimos inerentes a essa condição no prazo de 6 (seis) meses contados da comunicação da decisão ${ }^{255}$.

Além dos casos colombianos, tais técnicas de decisão já tinham sido adotadas em litígios estruturais no Canadá relativo aos direitos de educação em língua francesa, no qual a Suprema Corte decidiu que esse modelo decisório é mais deferente à autoridade e expertise do Poder Executivo, que pode escolher os meios mais adequados para se atingir o fim estabelecido, do que uma decisão judicial detalhada e fechada relativa a tema sobre o qual o Judiciário possui pouco conhecimento técnico ${ }^{256}$.

Antes mesmo da jurisprudência canadense, os Estados Unidos já haviam adotado essa prática em diversos casos de situações de inconstitucionalidade que exigiam mudanças complexas, gradativas e prolongadas, como nos casos da segregação escolar de Brown vs Board of Education of Topeka e os casos das reformas das prisões americanas ${ }^{257}$.

É importante destacar que a adoção desse modelo decisório exige um constante monitoramento e acompanhamento judicial das medidas adotadas pelos demais poderes, sob pena de ineficácia da decisão.

Nesse sentido, esse acompanhamento pode ser realizado através de atos públicos de seguimento, como a realização de audiências públicas e de divulgação de resultados e/ou prestação de contas.

O modelo de medidas flexíveis sujeitas à supervisão judicial requer, ainda, uma mudança de postura por parte do juiz constitucional. Com efeito, ao invés de impor medidas de execução unilateralmente, deve o magistrado discutir as medidas com os envolvidos,

\footnotetext{
${ }^{254}$ CORTE CONSTITUCIONAL DA COLÔMBIA. Terceira Sala de Revisão. Sentença T 153-98. p. 81. tradução livre.

${ }^{255}$ CORTE CONSTITUCIONAL DA COLÔMBIA. Terceira Sala de Revisão. Sentença T -25-04. p. 100. tradução livre.

${ }^{256}$ ROULEAU, Paul S.; SHERMAN, Lindsey. Doucet-Boudreau, dialogue and judicial activism: tempest in a teapot? Ottawa Law Review: V. 41.2. 2010. p. 176.

${ }^{257}$ Cf. WEAVER, Russel. The rise and decline of structural remedies. San Diego Law Review: V. 41, 2004.
} 
solicitando informações, estabelecendo, de comum acordo, o cronograma e os prazos para implementação das medidas, dentre outras circunstâncias.

\section{A EFICÁCIA DAS DECISÕES}

No que toca à eficácia das decisões, é importante ressaltar que decisões estruturais possuem efeitos que decorrem diretamente das ordens contidas na decisão e efeitos indiretos e de longo prazo, como os incentivos para criações de organizações sociais destinadas a buscar a efetivação dos direitos tutelados e para o ajuizamento de novas ações pelos vencedores da demanda, que passam a atuar na condição repeat players como estratégia para alcançar mudanças sociais ${ }^{258}$.

Desta feita, conforme mencionado acima, a decisão no caso Brown vs. Board of Education, proferida em 1954, ainda não tinha eliminado a segregação racial nas escolas norteamericanas em meados da década de 1960. Apesar disso, produziu efeitos simbólicos e práticos de longo prazo que não apenas acabou com a segregação racial nas escolas dos Estados Unidos como também auxiliou a impulsionar o movimento dos direitos civis dos negros naquele país.

No que toca ao contexto colombiano, os professores César Rodríguez e Diana Franco também defendem a existência de efeitos diretos e indiretos, instrumentais e simbólicos decorrentes dessas decisões estruturais ${ }^{259}$.

No caso específico do deslocamento forçado de pessoas, esses últimos autores destacam, dentre outros, a produção dos seguintes efeitos: a) o efeito de criação ou de delimitação do problema; $b$ ) o desbloqueio institucional; $c$ ) o efeito deliberativo; $d$ ) o efeito ou eficácia prática na política pública e $e$ ) o efeito ou impacto social ${ }^{260}$.

O efeito criador foi responsável por conferir visibilidade e urgência ao tema, moldando a forma como os agentes sociais veem o problema e definindo-o em termos jurídicos (efeito simbólico). Além disso, ele também cria práticas sociais através da atividade dos grupos com

\footnotetext{
258 Cf. EPP, Charles. Law as an instrument of social reform. The Oxford Handbook of Law and Politics. 2008. Chapter 34. p. 595-613.

${ }^{259}$ Cf. RODRÍGUEZ, César Garavito; FRANCO, Diana. Cortes y Cambio Social: como la Corte Constitucional transformó el desplazamiento forzado en Colombia. Bogotá: Centro de Estudios de Derecho, Justicia y Sociedad, 2010.

260 ibidem.
} 
interesse na execução da decisão, que passam a participar ativamente do processo, litigando nesse campo social com os demais atores (efeito instrumental) ${ }^{261}$.

No caso, observou-se, após as audiências públicas posteriores à decisão, um significativo aumento do número de notícias publicadas na imprensa escrita, as quais estavam localizadas nas seções mais gerais dos periódicos de maior circulação, que tratam das questões nacionais ${ }^{262}$. Esse fato demonstra claramente como a questão do deslocamento forçado de pessoas passou a ser tratada como assunto de interesse nacional e de relevante interesse público.

Em relação ao segundo efeito, ele decorreu de ordens emitidas pela Corte que promoveram o desbloqueio dos canais institucionais, o que foi feito através de medidas instrumentais diretas que provocaram reações imediatas nas autoridades estatais demandadas ${ }^{263}$.

Tais medidas consistiram, basicamente, na exigência de alocação de recursos orçamentários calculados pelo próprio Governo, os quais sofreram significativo aumento, e de produção de relatórios e informativos básicos sobre a situação do deslocamento interno ${ }^{264}$.

Ademais, César Rodríguez e Diana Franco constataram, a partir da análise de fatos posteriores à decisão, mudanças no funcionamento da Comissão para Atendimento Integral às Vítimas do Deslocamento Forçado (CNAPD), que retomou regularmente suas atividades em março de 2004, logo após o julgado, depois de longos anos de inatividade ${ }^{265}$.

Já o efeito deliberativo decorreu do estabelecimento de um diálogo entre o Governo, a sociedade e Corte, em especial nos atos subsequentes à decisão. Nesse sentido, o principal mecanismo de diálogo com a Corte foram as audiências públicas realizadas, atos públicos que serviram como mecanismo do debate democrático, prestação de contas, publicidade e transparência no desenho e avaliação da política pública do deslocamento forçado de pessoas ${ }^{266}$.

No que toca ao efeito da decisão na política pública, os dados estatísticos apresentados pelo próprio Governo demonstram que os recursos destinados aos desalojados sofreram significativos acréscimos após a decisão, tendo passado de uma média de 76.731 milhões de

\footnotetext{
261 RODRÍGUEZ, César Garavito; FRANCO, Diana. Cortes y Cambio Social: como la Corte Constitucional transformó el desplazamiento forzado en Colombia. Bogotá: Centro de Estudios de Derecho, Justicia y Sociedad, 2010. p. 93-94.

262 idem, p. 98-99.

263 idem, p. 130.

264 idem, p. 133-141.

265 idem, p. 155.

266 idem, p. 172-175.
} 
pesos no período de 1995 a 2003 para 731.343 no interregno de 2004 a 2008. Apenas no ano de 2008, considerado isoladamente, foram destinados 1.021 .936 bilhões de pesos ${ }^{267}$.

Por último, no campo do efeito ou do impacto social, embora tenha sido constatada alguma melhoria nos direitos das vítimas dos deslocamentos forçados, como nos campos da saúde, educação e atendimento emergencial, ainda há muito a se evoluir. Em diversas áreas como alimentação, direito à geração e recebimento de renda adequada e reparação, os avanços ainda são poucos ${ }^{268}$.

Não obstante, a decisão apresentou melhorias, sobretudo no que toca ao desbloqueio institucional e ao aumento de recursos, além da perspectiva simbólica e de alteração da percepção das pessoas sobre o assunto. Outrossim, acredita-se que os efeitos à longo prazo serão maiores e melhores, tal como nos casos das questões raciais nos Estados Unidos.

\section{CONSIDERAÇÕES FINAIS}

As graves violações de direitos fundamentais decorrentes de falhas estruturais do Estado exigem a adoção de decisões estruturais flexíveis, tal como realizado nos Estados Unidos, Canadá e, mais recentemente, na Colômbia, através do instituto do estado de coisas inconstitucional.

Embora essas decisões sejam consideradas ativistas, é importante destacar que elas normalmente não envolvem grandes questionamentos acerca da existência ou conteúdo dos direitos fundamentais em disputa. Na maioria dos casos, a grande questão jurídica é saber como concretizar direitos em face da reiterada inércia e omissão estatal.

Em relação às hipóteses e aos limites dessas decisões, elas devem ser adotadas em casos de reiterada inércia do Poder Público, nos quais haja urgência na prolação de medidas mais incisivas para proteção dos direitos dos indivíduos. Além disso, elas não são cabíveis quando a situação puder ser resolvida mediante decisão simples, exigindo, ainda, certo grau de consenso sobre os direitos objetos das ações e a observância de critérios de subsidiariedade e proporcionalidade.

\footnotetext{
${ }^{267}$ RODRÍGUEZ, César Garavito; FRANCO, Diana. Cortes y Cambio Social: como la Corte Constitucional transformó el desplazamiento forzado en Colombia. Bogotá: Centro de Estudios de Derecho, Justicia y Sociedad, 2010. p. 212-213.

268 idem, p. 254-269.
} 
No que toca à implementação das medidas, as decisões estruturais devem ser aplicadas através de ordens abertas e flexíveis, sujeitas a monitoramento judicial.

Desta feita, elas poderão produzir efeitos diretos e imediatos e efeitos indiretos e de longo prazo, tal como constatado nas questões raciais nos Estados Unidos.

No que toca à experiência colombiana, a declaração do estado de coisas inconstitucional no caso do deslocamento forçado de pessoas produziu relevantes efeitos de desbloqueio dos canais institucionais, aumento de recursos orçamentários e estabelecimento de diálogo entre o Governo, a Corte e a sociedade.

\section{REFERÊNCIAS}

ARIZA, Libardo José. The Economic and Social Rights of Prisoners and Constitutional Court Intervention in the Penitentiary System in Colombia. In: MALDONADO, Daniel Bonilla.Constitutionalism of the Global South. The Activist Tribunals of India, South Africa and Colombia. New York: Cambridge University Press, 2013.

BARROSO, Luís Roberto. A razão sem voto: o Supremo Tribunal Federal e o Governo da Maioria. In: Jurisdição constitucional e política. Coord.: SARMENTO, Daniel. Rio de Janeiro: Fortense, 2015.

. O novo direito constitucional brasileiro. Ed. Fórum: Belo Horizonte, 2012.

BICKEL, Alexander M. The Least Dangerous Branch: The Supreme Court at the Bar of Politics. 2 ed. Yale University Press: New Haven, 1962.

BRANDÃO, Rodrigo. Supremacia judicial versus diálogos constitucionais: a quem cabe a última palavra sobre o sentido da Constituição? Rio de Janeiro: Lumen Juris, 2012

CAMPOS, Carlos Alexandre de Azevedo. Da inconstitucionalidade por omissão ao

"Estado de Coisas Inconstitucional". Tese de Doutorado. UERJ: Rio de Janeiro, 2015

COLÔMBIA. Jurisprudência da Corte Constitucional. Disponível em: $<$ http://www.corteconstitucional.gov.co/>.

EPP, Charles. Law as an instrument of social reform. The Oxford Handbook of Law and Politics. 2008. Chapter 34. 
FISS, Owen. Foreword: The Forms of Justice. Harvard Law Review. Vol. 93. nº 1. nov. 1979.

FRIEDMAN, Barry. The Birth of an Academic Obsession: The History of The Countermajoritarian Difficulty, Part Five. 112 Yale Law Journal. 153. 2002-2003.

MARSHALL, Willian P. Conservatives and the seven sins of judicial activism. University of Colorado Law Review, Vol. 73, 2002.

RODRÍGUEZ, César; FRANCO, Diana. Cortes y Cambio Social: como la Corte Constitucional transformó el desplazamiento forzado en Colombia. Bogotá: Centro de Estudios de Derecho, Justicia y Sociedad, 2010.

ROULEAU, Paul S.; SHERMAN, Lindsey. Doucet-Boudreau, dialogue and judicial activism: tempest in a teapot? Ottawa Law Review: V. 41.2. 2010. p. 176.

SABEL, Charles F.; SIMON, William H. Destabilization rights: how public law litigation suceeds. Harvard Law Review. 117. February, 2004.

SUNSTEIN, Cass R; VERMULE, Adrian. Interpretation and Institutions. John M. Olin Program in Law and Economics Working Paper. No. 156. Chicago, 2002.

WALDRON, Jeremy. Law and disagreement. Oxford University Press: Nova Iorque, 2004. . WALDRON, Jeremy. The core of the case against judicial review. The Yale Law Journal, 115

WEAVER, Russel. The rise and decline of structural remedies. San Diego Law Review: V. 41, 2004.

\section{STRUCTURAL REMEDIES, CIVIL RIGHTS AND THE UNCONSTITUTIONAL STATE OF AFFAIRS}


This Article has the purpose to analyze the structural actions involving serious violations of fundamental rights, which were nominated as unconstitutional state of affairs by the jurisprudence of colombian Constitutional Court. At first, the purpose was to investigate the origin of these actions starting from the decision reached in Brown vs Board of Education, by the Supreme Court of the United States, as well as delimitate the concept of these actions, to avoid the banalization of this instrument. It was tried to face the main critics to these actions, as those who refer to the activist feature of the judicial decisions that interfere in public policies. Under a more pragmatic perspective, the study investigated the enforcement methods applied to these actions, which include judicial flexible remedies and monitoring, as well as the effective results of the decisions.

Keywords: Civil rights. Structural remedies. Unconstitutional State of Affairs. 